\title{
PENGAJIAN DASAR AL-QUR'AN TRADISIONAL VERSUS BARU DI SULAWESI SELATAN (STUDI TENTANG BUKU TUNTUNAN BELAJAR MENGAJAR AL-QUR'AN).
}

\author{
Oleh : Muhammad As'ad
}

\section{I}

Al Qur'an, sebagai tuntunan hidupumat Islam yang harus diaplikasikan dalam kehidupan schari-hari, diturunkan dalam bahasa Arab dan tidak bisa ditcransliterasikan dalam bahasa lain. Karcnanya merupakan kcsulitan bagi orang orang Ajam dalam mcmpelajari bacaannya dan memahami kandungannya. Usaha untuk mengatasi kesulitan itu mendapat pcrhatian yang cukup sejak dahulu; dengan demikian scjarah timbul dan berkembangnya pengajian dasar Al Qur'an di Sulawesi Selatan berbarengan dengan scjarah perkembangan agama Islam di dacrah ini.

Pengajian dasar Al Qur'an yang tcrgolong tradisional, dengan sistem mengeja, dilakukan sejak dahulu. Namun suatu kenyataan yang kurang menggembirakan pada pasc-pase terakhir ini pengajian tersebut cenderung menurun secara kuantitatif yang berakibat membengkaknya porsi umat Islam (anak/rcmaja) yang tidak mcmiliki kemampuan membaca Al Qur'an dengan baik dan lancar. Dari suatu studi empirik yang dilakukan oleh Universilas Hasanuddin pada tahun 1985 dapat disimpulkan bahwa sekitar 2,6 juta anak di bawah umur 13 tahun di Sulawesi Selatan perlu mendapat pclajaran baca tulis huruf Al Qur'an.

Sebagai antisipasi gejala yang kurang mcnggembirakan tersebut, pengajian dasar Al Qur'an yang tergolong baru bcrmuncu- lan di bcrbagai tempat, utamanya di kotakota. BahkanPcmerintahdi tingkatpropinsi Sulawesi Sclatan mengadakan suatu usaha tcrprogram, yaitu Gerakan Bebas Buta Aksara Al Qur'an (GBBAQ) dan usahausaha peningkatan pemahaman, penghayatan dan pengamalan Al Qur'an. Bcrkaitan dengan itu kebutuhan atas buku pedoman membaca/mengajar Al Qur'an yang tcpat dan cepat sudah terasakan yang sclanjutnya bermunculan berbagai buku tuntunan tersebut.

Penel iti an tentang pern ak ai an buku tuntunan telah diadakan oleh Balai Penelitian Lektur Keagamaan Ujung Pandang, namun gambaran yang terungkap masih sangat terbatas. Gambaran yang jelas mengenai hal itu mcrupakan input dan informasi yang penting dan bcrguna untuk pembinaan dan pengembangan pengajian Al Qur'an yang rclcvan dengan perkembangan dan kemajuan masyarakat. Untuk itu Balai Penelitian Lcklur Keagamaan Ujungpandang dalam tahun anggaran 1992/1993 mengadakan suatu penelitian di berbagai daerah di $\mathrm{Su}$ lawesi Sclatan. Hasil penelitian ini diharapkan dapat memberi gambaran yang mcnyeluruh untuk wilayah Sulawesi Selatan.

Lokasi penelitian (sebagai sample) dipilih 5 Kabupaten/Kotamadya secara purpossif dengan mcmperhatikan latar bclakang ctnis dan kondisi sosial ke- 
agamaan penduduknya. Pada tiap-tiap kabupaten/kotamadya dipilih dua kecamatan sebagai lokasi sampel. Teknik yang dipcrgunakan dalam pengumpulan data di lapangan adalah : wawancara (berpedoman dan bebas), observasi dan studi naskah/ kcpustakaan. Data yang terkumpul dianalisissccarakuantitatif, denganmengadakan intcrprestasideskriptif dengan memperhatikan hubungan variabel yang bermakna.

\section{II}

Penduduk asli Sulawesi Selatan terdiri dari berbagai etnis yang tcrkonscntrasi pada daerah-daerah tertentu.

Etnis Makassar yang mendiami bagian selatan jazirah Sulawesi Selatan (Gowa, Jcncponto, Takalar dan Bantaeng) serta Sclayar. Etnis Bugis mendiami daerah yang paling luas, meliputi berbagai Kabupatcn, sepcrti Barru, Sidrap, Soppcng, Bone dan Luwu. Etnis Mandar mendiami bagian pesisir barat laut jazirah Sulawesi Selatan (Polmas, Majcnc dan Mamuju). Dan etnis Toraja mendiami KabupatenTanahToraja.

Etnis Makassar, Bugis dan Mandar tcrmasuk pemeluk Islam yang fanatik. Sejak agama Islam dilcrima sebagai agama rcsmi kcrajaan-kerajaan lokal maka sariat Islam menjadi bagian integral dalam sistcm budayanya. Nilai-nilai agama bcrintegrasi dengan nilai budaya, sehingga terkadang dalam suatu pranata sosial susah $\mathrm{mcm}$ bedakanunsur agama dengan unsurbudaya. Kerajaan Gowa memegang pcranan penting dalam penyiaran agama Islam di Sulawesi Selatan dengan mengajak kerajaan-kerajaan lainnya untuk menerimanya lewat kcwibawaan dan kekuasaannya.

Masyarakat Islam di Sulawesi Selatan masih banyak yang memclihara tradisi keagamaan yang diwarisi dari orang-orang tuanya, meskipun pelaksanaannya kebanyakan secara simpel dan praktis berbeda dengan yang telah dilaksanakan dahulu. Tradisi-tradisi yang berkaitan dengan siklus hidup masih banyak dipclihara dengan baik. Pcmbacaan Kitab Al Barazanji berkaitan dengan upacara syukuran masih seringdilakukan, demikian juga berkaitan dengan upacara perkawinan. Pcnammatan Al Qur'an yang diakhiri dengan tahlilan berkaitan dengan kematian seseorangjuga masih banyak dilaksanakan. Di Ujungpandang sendiri, sebagai masyarakat kota, masih banyak yang memclihara upacara-upacara lerscbut.

Hanya saja di Kabupatcn Enrckang, pola tingkah laku keagamaan mempcrlihatkan pcrubahan yang jelas sebagai pengaruh organisasi Muhammadiyah yang banyak diikuti oleh masyarakatnya dan pengaruh gerakan DI/TII yang pernah bcrkuasa pada scbahagian besar daerah ini. Sebelumnya, masyarakat Enrckang masih banyak yang menganut upacara mistisis, misalnya pada upacara kematian berbagai upacara dilaksanakan, akan tctapi sekarang ini kebanyakan hanya ringkas dan singkat berupa acara ta'ziah dalam bentuk ceramah.

Acara ta'ziah sclama tiga hari bcrturutturul banyak dilakukan olch masyarakat di kota-kota yang bcrintikan ceramah ta'ziah. Namun kemampuannya untuk menggescr upacara lama sepcrti telah dikemukakan masih memcrlukan waktu lama, kalau toh hal itu akan terjadi, tcrutama di kalangan masyarakat pedesaan.

Pada masa dahulu, pcmbacaan Al Qur'an berkaitan dengan kematian, selain dimaksudkan pengiriman pahala bagi orang 
mcninggal, juga bcrfungsi sebagai wadah/ lcmbaga musabaqah tilawatil Qur'an. Pembacaan Al Qur'an tidak hanya dilakukan secara bersama-sama, juga dilakukan secara bergantian dengan lagu dan tajwid. Para Qari' saling menegur bila bacaan salah sehingga tcrkadang scscorang kcringatan dan mcrasa malu bila bacaannya kurang lancardan tajwidnya kurang mantap. Mcrupakan kcbanggaan scscorang bila mampu tampil dengan baik, sckaligus kcbanggaan bagi orang tua dan gurunya. Sebagai wadah pengajian, hal ini mendorong anak-anak bcrlomba-lomba untuk belajar mengaji sckaligus mcrupakan salah satu pendorong bagi orang tua untuk mcmperhatikan apakah anaknya rajin mengaji alau tidak. Banyak orang tua yang tidak scgan memukul anaknya karcna malas pcrgi mengaji.

Kernampuan mcmbacaAl Qur'an mcrupakan salah satu pencntu gengsi sosial. Orang yang pintar membaca Al Qur'an mendapatkan penghargaan tertentu dari masyarakat. Adatradisi di kalanganmasyarakat Mandar bahwa scscorang yang tidak dapal mengaji mendapat penilaian negatif, sebagai contoh calon mcrtua scbelum menerima calon mantu tcrlcbih dahulu mcnanyakan apakah ia bisa mengaji atau tidak. Namun falsafah ini mulai ditinggalkan oleh masyarakat pendukungnya, utamanya di kota-kota.

Guru-guru mengaji mendapat penghormatan dari masyarakat, selain karcna kemampuannya membaca Al Qur'an juga karcna kcrclaannya mengajar anak-anak orang lain tanpa gaji/honor. Namun sebagai imbalan dan sebagai pendidikan bagi anakanak mengaji sendiri, mereka tcrkadang disuruh bckcrja oleh guru mengajinya, seperti mengangkat air, mencari kayu bakar atau mcmbersihkan rumah, baik sebelum atau scsudah mengaji.

Pcnghormatan dan ketaatan anak mengaji (murid, santri) kepada gurunya scnantiasa dipelihara, tcrkadang anak lebih lakut kepada gurunya dibanding kepada orang tuanya. Orang tua sang anak juga hormat dan bcrtcrima kasih kepada guru mengaji yang mengajar anaknya. Mcskipun tanda tcrima kasih mereka jika diukur secara material sangal kurang. Salah satu wujud terima kasih dan hormat orang tua ialah diadakannya upacara khatam Qur'an. Upacara sepcrti ini masih didapati dikalangan masyarakat Sulawesi Selatan, tctmasuk di Ujung Pandang dewasa ini, kebanyakan dirangkaikan dengan perkawinan anak mengaji, tcrkadang dirangkaikan dengan acara khitanan dan terkadang diadakan tersendiri. Dalam masyarakat Bugis, sepcrti di Kabupatcn Soppeng, pada upacara ini guru mengaji akan mendapatkan sepcrangkat hidangan tcrdiri dari kue tradisional bcrmacam-macam. Sedang pada masyarakat Makassar, selain perangkat hidangan scaipa kanrc maudu juga seperangkat pakaian.

Pcrkcmbangan pengajian dasar Al Qur'an berlangsung sejak dahulu mengiringi penyebaran Agama Islam. Dapat diduga, bahwa pengajian Al Qur'anbcrkembang di kalangan masyarakat mula-mula di dalam istana di bawah bimbingan penyiar Islam, kemudian dikembangkan di rumahrumah oleh murid-murid yang telah berkemampuan pengajar, apakah mengajar anggota rumah tangganya sendiri atau menerima anak-anak tctangga. Disebutkan bahwa pada tahun 1636 M. Sayyid Ba'lawi 
mendirikan pengajian di Bontoala atas persetujuan raja Gowa.

Sejak dahulu sistem pengajian dasar Al Qur'an yang dikenal oleh masyarakat Sulawesi Selatan adalah yang dilakukan dalam bentuk halaqah dengan buku pedoman Qaedah Bagdadiyah (sistem Mengeja). Lembaga pengajian demikian, dalam tulisan ini disebut pengajian tradisional, berjalan terus melewati beberapa abad dan sampai sekarang masih banyak dijumpai di kalangan masyarakat. Sistem dan metode pengajaran tidak mengalami perubahan yang berarti. Guru mengaji mengajar muridnya (mengeja) dengan mempergunakan bahasa induknya (bahasa Bugis atau bahasa Makassar), jarang yang menggunakan bahasa Indonesia. Mengeja dengan bahasa induk sang guru dapat dimengerti oleh anak-anak yang tidak seetnis dengan gurunya. Mengeja dengan bahasa Bugis paling banyak dilakukan, selain di daerah Bugis juga di daerah Mandar.

Pengajian tradisional ini dilakukan di rumah-rumah sang guru dengan menyiapkan ruangan dalam rumahnya atau serambi/kolong rumahnya. Waktu yang dipilih kebanyak pagi dan sore. Perkembangan yang terjadi bagi pengajian seperti ini ialah berdirinya pengajian-pengajian yang terkait dengan kepengurusan masjid mushallah dan dilaksanakan di masjid/ mushallah. Tambahan pelajaran lain, misalnya do'a-do'a pendek, bacaan-bacaan dan praktek shalat diberikan kepada anak mengaji (murid). Alat-alat bantu berupa alattulismenulismulai memasuki lembaga pengajian Al Qur'an. Buku tuntunan/metode pengajaran yang dipergunakan tetap Qaedah Bagdadiyah. Pengajaran seperti ini dilakukan oleh guru mengaji yang memiliki pendidikan formal yang cukup. Pengajian seperti ini dijumpai di beberapa daerah termasuk di Ujung Pandang beriringan dengan pengajian di rumah-rumah.

Anggota masyarakat yang tergolong berkemampuan, seperti pejabat-pejabat, banyak yang menginginkan agar anaknya dapat diajar secara cfektif dan tanpa gangguan, menginginkan agar anaknya diajar membaca Al Qur'an di rumahnya. Mereka membutuhkan guru mengaji yang bersedia datang ke rumahnya untuk keperluan itu. Pengajian seperti ini, yang dikenal dengan pengajian privat, hanya didapati di Ujung Pandang.

Perkembangan baru yang menonjol bagi pengajiandasar Al Qur'an adalah munculnya di kalangan masyarakat buku Iqra' (metode Iqra'). Metode ini dikenal oleh masyarakat Sulawesi Selatan kurang lebih dua tahun tcrakhir ini, berbarengan dengan digalakkannya Gerakan bebas Buta Aksara Al Qur'an di Sulawesi Selatan. Yang sangat menarik ialah bahwa buku Iqra' ini diperkenalkan sekaligus diperkenalkannya pengelolaan pengajian Al Qur'an yang tergolong modern, yaitu pembentukan TKA/TPA.

Pcngclolaan sebuah TKA/TPA dengan baik memerlukan dana yang cukup untuk beaya operasional, seperti penyediaan gcdung dan mobiler dan sekedar jaminan hidup bagi gurunya. Karena itu uang pangkal, uang pendaf'taran dan uang bulanan dipcrlukan untuk kelancaran pengelolaannya. Orang tua santri perlu menyiapkan dana yang rclatif banyak untuk keperluan pembayaran itu dilambah penyediaan buku-buku dan pakaian seragam. Berkaitan dengan itu. TKA/TPA 
yang berada di tengah-tengah masyarakat yang rata-rata sosial ekonominya tergolong baik dan memiliki kesadaran pendidikan yang tinggi mengalami kemajuan.

Meskipun buku/metode Iqra masih tergolong baru dalam masyarakat di Sulawesi Sclatan namun sudah menyebar di seluruh kabupaten/kotamadya. Hanya saja penycbarannya sangat tcrbatas pada kebanyakan dacrah. Scpcrti di Majene, bclum dikctcmukan pengajian yang betul-betul hanya tuntunan tersebut yang dipcrgunakan. Lembaga Pengajian yang mempergunakannya juga mempergunakan Qacdah Bagdadiyah, jadi baru bersifat percobaan bagi murid tcrtentu. Di Ujung Pandang sudah banyak pengajian yang mempergunakannya. TK A/TP A yang ada baik yang bersifat bentukan baru maupun peralihan dari bentuk lama mempergunakan buku tuntunan ini. Di Enrckangbanyak pengajian yang tadinya memakai Qaedah Bagdadiyah beralih kepada mctode Iqra'. Pengajian tradisional dengan Qacdah Bagdadiyah mulai tergeser oleh pengajian yang memakai mctode Iqra', bahkan di kecamatan Baraka yang masih bcrpola pikir kolcktivismc, scmua pengajian yang mcnggunakan metodc Baqdadiyah dirobah dengan menggunakan metode Iqra'.

Sckolah, sebagai lembaga pendidikan yang di dalamnya diajarkan pclajaran membaca Al Qur'an sebagai bagian dari pendidikan agama Islam pcrlu ditampilkan dalam makalah ini sebagai salah satu bentuk lembaga pengajian Al Qur'an. Pendidikan agama Islam pada sckolah umum negeri diatur sedemikian rupa bcrdasarkan GBPP Kurikulum Pendidikan Agama islam 1975 yang discmpurnakan.
Berdasarkan kurikulum tersebut, pclajaran membaca Al Qur'an bagi murid SD baru diberikan pada kelas IV yang intinya adalah pengenalan hurufdan tanda baca Al Qur'an.

Pada umumnya lembaga pengajian Al Qur'an di sekolah belum memperlihatkan hasil scsuai dengan tujuan/harapan. Kebanyakan murid-murid yang mampu membaca Al Qur'an mempcrolehnya dari luar sekolah, sepcrti pengajian tradisional atau pengajian di masjid. Anak yang tidak tcrjangkau oleh pengajian di luar sekolah, yang hanya mcmperoleh pelajaran membaca Al Qur'an di sekolah kemampuan membacanya sangat minim.

Usaha untuk meningkatkan kualitas umat bcragama, khususnya Umat Islam dilakukan oleh Pcmerintah secara terprogram lewat Gcrakan Bcbas Buta Aksara Al Qur'an (GBBAQ). Gcrakan ini secara sercntak bcrgema di seluruh wilayah Sulawesi Selatan. Pelaksanaan GBBAQ lewat jalur formal secara bcrtahap dengan sasaran sckolahsckolah binaan yang telah ditentukan, baik tingkat SD, SLTP maupun tingkat SLTA. Untuk kcbcrhasilannya tcrdapat saling pengaruh antara lembaga pengajian di luar sekolah dengan pengajian di sckolah.

Ada liga instansi pemerintah yang eral kaitannya dengan lembaga pengajian Al Qur'an, utamanya dalam hal ini Gcrakan Bcbas Buta Aksara Al Qur'an, yaitu Dcpartcmen Agama, Departemcn Dikbud dan Departemen Dalam Negeri. Tanggung Jawab opcrasionalnya berada di bawah Kanwil Dcpag Sulscl dan dalam pclaksanaanna didukung oleh Kanwil Dcpdikbud dan Pemerintah Dacrah Propinsi Sulawesi Selatan. Masing-masing kabupatcn/Koiamadya mclaksanakannya 
dengan irama dan intensitasnya sehingga membuahkan hasil yang cukup menggembirakan. Sampaipadaawaltahun 1993 sudah 13 Kabupaten/Kotamadya di Sulawesi Selatan telah dinyatakan bebas buta aksara Al Qur'an.

Meskipun pernyataan bebas buta aksara Al Qur'an yang ditetapkan berdasarkan Surat Keputusan Kepala Kanwil Depag Propinsi Sulawesi Selatan cenderung bersifat politis, bukan secara mutlak, namun didukung oleh fakta yang menunjukkan keberhasilan gerakan tersebut. Karena pernyataan itu demikian adanya, maka setelah suatu kabupaten/kotamadya dinyatakan bebas buta aksara Al Qur'an tidaklah berarti selesai masalah. Akan tetapi pernyataan itu harus dijadikan cambuk untuk mencapai kenyataan demikian secara optimal.

Dampak positiflain dari gema gerakan tersebut, ialah perkembangan pengajian Al Qur'an secara kualitatif dan kuantitatif. Perhatian pemerintah yang tinggi terhadap lembaga pengajian Al Qur'an merupakan salah satu faktor pemacu semangat pengabdian pengelolah lembaga pengajian, baik secara perorangan maupun secara kelembagaan/organisasi. Pada suatu sisi jumlah lembaga pengajian semakin meningkat dan pada sisi lain administrasi pengelolaan pengajian tradisional juga banyak yang mengalami peningkatan, yang ditandai dengan pemberi annamalembaga pengaj i an tradisional serta perbaikan struktur kepengurusannya.

Selain ketiga instansi pemerintahan tersebut, yang berpartisipasi dalam pembinaan dan pengembangan pengajian Al Qur'an banyak instansi/lembaga swasta, seperti organisasi sosial keagamaan, lembaga keagamaan lainnya dan organisasi kemasyarakatan (PKK). Badan Komunikasi pemuda Masjid Indonesia (BKPMI)
Wilayah Sulawesi Selatan banyak berjasa dalam memasyarakatkan metode Iqra' seiring dengan pemasyarakan bentuk pendidikan Al Qur'an yang lebih modern (TKA/TPA).

\section{III}

Qaedah Bagdadiyah adalah buku tuntunan tertua yang dikenal oleh masyarakat untuk mengajarkan membaca Al Qur'an. Namun karena perkembangan masyarakat, berbagai pihak merasakan bahwa penerapan buku tersebut selama ini mulai dirasakan kurang relevan. Karena itu bermunculanlah berbagai buku tuntunan baru. Di antara buku-buku tuntunan yang dijumpai di Sulawesi Selatan, yang banyak mendapat perhatian adalah4 buahbuku, yaitu: Qaedah Bagdadiyah (penyusunnya sudah tidak diketahui), Buku Iqra' cara cepat belajar membaca Al Qur'an oleh As'ad Humam, Al Barqy Belajar Baca Tulis Al Qur'an oleh Drs. Muhadjir Sulton dan Bimbingan Membaca Al Qur'an Tingkat Dasar oleh Departemen Agama RI.

Apabila kita perhatikan materi/pokok bahasan dalam buku tuntunan belajar membaca Al Qur'an pada garis besarnya dapat dikelompokkan dalam 3 bahasan utama, yaitu :

1. pengenalanhurufhijaiyah (bentuk, bunyi dan namanya),

2. pengenalan tanda baca yangmenentukan bunyi huruf, dan

3. aturan membaca dengan baik dan benar (ilmu tajwid).

Pengenalan huruf hijaiyah dan tanda baca dapat dikatakan sebagai pengetahuan dasar, sedang pengenalan aturan tajwid merupakan pengetahuan lanjutan. Namun demikian dalam mempelajari bacaan Al Qur'an ketiga bahasan tersebut merupakan suatu kesatuan yang tak terpisahkan. Apa- 
bila kita akan menambah pokok bahasan yang tidak kurang pentingnya, maka bahasan ke-4 adalah pclajaran menulis huruf Al Qur'an.

Untuk mempcrsingkat makalah ini keempat buku tuntunan tersebut diberikan initial tersendiri, yaitu QB (Qaedah Bagdadiyah), MI (Metodc Iqra'), TB (Thariqah Barqiyah) dan BM (Bimbingan Mcmbaca Al Qur'an Tingkat Dasar).

Dalam memperkenalkan bentuk dan bunyi huruf hijaiyah QB menuangkannya dalam suatu unit bahasan, scdang kctiga lainnya mcmperkenalkannya secara beransur-ansur, hanya saja MI mcmperkenalkannya berdasarkan urutan yang lazim, BM dan TQ bukan berdasarkan urutan yang lazim. Jumlah huruf Hijaiyah yang diperkenalkan dalam QB sebanyak 30 buah termasuk ( ) dan ( ), sedang dalam BM 29 buah, tidak termasuk ( ), dan dalam MI dan TB hanya 28 buah karena tidak dimasukkan ( ) dan ( ).

Memperkenalkan nama-nama huruf hijaiyah dianggap penting dalam QB karena mcrupakan dasar sistcm mengeja yang dipergunakannya, sedang ketiga lainnya tidak dirasa penting. Olchnya itu QB memuatnya pada unit pertama sedang lainnya mcmperkenalkannya setel ah bentuk dan bunyi huruf-huruf itu diketahui. Kecuali BM bunyi huruf dipcrkcnalkan dengan tandabacafathah( $\sim)$; ketiganya memperkenalkan tanda baca secara beransur-ansur, sedang BM mcmperkenalkannya sekaligus.

Dalam memperkenalkan huruf-huruf hijaiyah itu QB dan MI mula-mula mcmperkenalkannya dalam kcadaan tunggaldan sctclah pengenalan demikian dinilai mantap baru pindah pada penyambungan/ rangkaian huruf. Adapun TB dan BM memperkenalkan huruf dalam keadaan tunggal danberangkai sekaligus dalam suatu unit bahasan; bedanya TB memperkenal- kan huruf dalam rangkaian "semu" (semi SAS) sedang BM memperkenalkan rangkaian huruf, kemudian huruf tunggal lalu kembali dirangkai (SAS).

Sebagaimana kita ketahui, bahwa di antara huruf-huruf hijaiyah itu ada yang ham pi r bersam aan buny iny a sehingga terkadang sulit untuk membedakannya. Pembahasan ini dirasa penting sehingga hurufhuruf yang demikian ditampilkan dengan jelas dalam MI, TB dan BM, sedang QB tidak demikian sehingga membedakannya tergantung pada kcjelian guru yang mengajarkannya.

Ada 3 huruf yang mempunyai ciri khas tersendiri, terutama bila bcrtanda baca suk un, dal am bahasa Arab di i s ti 1 ahkan hu ruf mu'lal scdang dalam ilmu tajwid bisa dikatakan huruf mad karena erat kaitannya dengan mad, yaitu :

( ). Keempat buku tuntunan tersebut mcmbahasnya secara gamblang dikaitkan dengan cara membacanya dengan penyesuaian tanda baca huruf sebelumnya.

Berkaitan dengan mad, dalam Al Qur'an ada tanda baca tertentu, yaitu : ( ). Scmua buku tuntunan menyinggung tanda mad bcrupa ( ) dan ( ), adapun ( ) dan ( ) hanya disinggung dalam MI dan BM.

Bahasan lainnya adalah waqaf, cara membacanya dan tanda-tandanya. Cara mcmbaca pada waktu berhenti (waqat) dibahas dalam ketiga buku tuntunan tersebut kecuali dalam QB; hanya saja dalam BM khusus pada ( ) yang diungkapkan.

Pcmbahasan utama dalam ilmu tajwid, yaitu ( / ) dan ( ) bcrtcmu huruf scsudahnya, apakah dibaca dengung alau tidak dibahas secara gamblang dalam MI (dalam jilid V dan VI), scdang TB mcmbahasnya pada buku kedua (untuk SLTP, SLTA dan Orang Dewasa). Adapun QB dan BM dalam buku yang dibahas dalam laporan penelitian tidak dicantumkan. 
Dilihat dari segi materi bahasan, maka yang terinci dan terluas jangkauannya adalah MI, karenanya setelah santri menyelesaikan sampai jilid VI dihitung sudah tamat dan pelajaran berikutnya, membaca Al Qur'an 30 juz dihitung tadarus. Berbeda dengan buku tuntunan lainnya, sepcrti QB scorang anak mengaji baru dihitung tamat setelah menyclcsaikan bacaan Al Qur'an 30 juz, scdang mengulangi kembali baru dianggap tadarus.

Banyak hal-hal yang tidak dikemukakan pada buku tuntunan lainnya dikemukakan pada MI sepcrti ragam tulisan hamzah, ra dan mim dan cara membaca lafzul-jalalah. Meskipun demikian, ada bahasan yang dipcrhalikan TB tidak tcrmuat dalam MI, yaitu huruf-huruf putus yang didapati pada permulaan bebcrapa surah. Dalam TB dikemukakan secara simpcl bahwa huruf-huruf putus itu dibaca dengan mengembalikan pada nama huruf. Di samping itu QB memiliki ciri tersendiri, banyak kata-kata yang dikemukakan dalam bahasannya bcrkaitan dengan dasar-dasar pelajaran tata bahasa Arab (Qawaid), meskipun tidak dijelaskanistilah-istilahnya.

Satu-satunya buku tuntunan yang mencantumkan malcri bahasan cara menulis huruf Al Qur'an ialah TB. Kalau pada $1 \mathrm{~cm}$ baga pengajian yang mcnggunakan buku tuntunan lainnya diajarkan cara mcnulis huruf Al Qur'an, itu hanya pelajaran tambahan seperti pada TKA/TPA atau termuat dalam tuntunan selanjutnya sepcrti pada pelajaran di SD.

Perlu ditcgaskan kembali bahwa satusatunya buku tuntunan yang diterapkan dengan sistcm mengeja adalah QB.

Selain itu dikemukakan pula bahwa QB dan MI diterapkan dengan sistem pri- vat/modul, sedang TB dan BM diterapkan dengan sistcm klassikal. QB dan MI dalam bahasannya memakai sistcm syntesis, scdang BM dan TB memakai sistem SAS dan semi SAS.

Dari segi persepsi anak terhadap buku tuntunan, hanya QB karcna mcrupakansuatu kesatuan dengan Al Qur'an juz Amma (Qur'an kecil) maka dipandang sebagai Al Qur'an yang bcrnilai sakral, harus dipclihara dengan baik agar tcrhindar dari dosa, sedang kctiga buku lainnya dipandang oleh anak sama dengan buku pelajaran lainnya di sekolah.

\section{IV}

Gcrakan Bcbas Bula Aksara Al Qur'an yang digalakkan di Sulawesi Selatan sejak tahun 1989 tclah mcmpcrlihatkan hasil yang menggembirakan, dilandai dengan penctapan 13 kabupaten sebagai daerah bcbas buta aksara yang dalam waktu dekat akan disusul 10 kabupatcn/kolamadya lainnya. Oleh karcna pcrnyataan ini tidak berlaku mutlak maka penanganan selanjutnya sangat dipcrlukan. Kcbcrhasilan ini akibat kclerlibatansccaralangsungberbagai pihak, utamanyapihakpemcrintahdi samping guru mengaji itu sendiri. Meskipun guru mengaji tradisional mclakukan lugas mulia itu tanpa pamrih, namun uluran tangan pemcrintah, u tarn any a berupa bantuan material dapat lebih menggairahkannya, bantuan sclama ini yang belum mcrata karena keterbatasan kemampuan pcrlu ditingkatkan. Selain itu para orang tua anak pcrlu mengcluarkan infaq/shadaqahnya kepada guru-guru mengaji untuk mcngurangi beban hidupnya schingga pcrhatiannya kepada pengajian semakin tinggi. 


\section{KEPUSTAKAAN}

Abu Hamid Sistem Madrasah dan Psantren di Sulawesi Selatan, dalam Taufik Abdullah (ed) ; Agama dan Perubahan Sosial, Jakarta : CV. Rajawali, 1993.

As'ad Humam, dkk Buku Pcdoman Pengelolaan, Pcmbinaan dan Pengembangan TKA-TPA Nasional, Balai Penelitian dan Pcngambangan Sistem Pengajaran Baca Tulis Alquran Lembaga PengembanganTilawatil Qur'an Nasional, Jogyakarta, 1992.

BPLK Masuknya Islam di Sulawesi Sclatan, Laporan hasil Penelitian, Ujungpandang, 1986.
Bintarto, Prof. Drs. Interaksi Desa - Kota dan Permasalahannya, Ghalia Indonesia, Jakarta, 1983.

Dcpartcmen Agama RI Pendidikan Agama Islam untuk Murid Sckolah Dasar Kelas IV, Dirjen Pcmbinaan Kelembagan Agama Islam, Jakarta. 1991.

Mattulada Islam di Sulawesi Sclatan, dalam Taufik Abdullah (ed) Agama dan Pcrubahan Sosial, CV. Rajawali, Jakarta, 1983. 